\title{
Self-Consistent Cathode-Plasma Coupling and Role of the Fluid Flow Approach in Torch Modeling
}

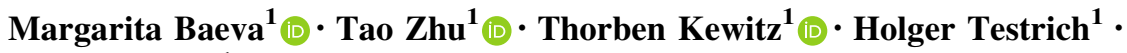 \\ Rüdiger Foest ${ }^{1}$
}

Submitted: 25 March 2021 / in revised form: 16 September 2021/Accepted: 16 September 2021/Published online: 26 October 2021 (C) The Author(s) 2021

\begin{abstract}
A two-dimensional and stationary magnetohydrodynamic model of a plasma spray torch operated with argon is developed to predict the plasma properties in a steady operating mode. The model couples a submodel of a refractory cathode and its non-equilibrium boundary layer to a submodel of the plasma in local thermodynamic equilibrium in a self-consistent manner. The Navier-Stokes equations for a laminar and compressible flow are solved in terms of low and high Mach number numerical approaches. The results show that the Mach number can reach values close to one. Simulations are performed for electric currents of $600 \mathrm{~A}$ and $800 \mathrm{~A}$, and gas flow rates of 40,60, and 80 NLPM. The plasma parameters obtained by the two approaches differ, and the differences become more pronounced for higher currents and gas flow rates. The arc voltage, the electric power, and the thermal efficiency from both the low and high Mach number models of the plasma agree well with experimental findings for a current of 600 A and a flow rate of 40 NLPM. For higher currents and gas flow rates, the results of the low and high Mach number models gradually differ and underline the greater appropriateness of the high Mach number model.
\end{abstract}

Keywords arc-cathode interaction - compressible flow · LTE plasma $\cdot$ Ma number $\cdot$ magnetohydrodynamic model . plasma spray torch

Margarita Baeva

baeva@inp-greifswald.de

1 Leibniz Institute for Plasma Science and Technology, FelixHausdorff-Strasse 2, 17489 Greifswald, Germany

\section{Introduction}

Plasma spray torches are widely spread in industrial applications concerning the deposition of protective and functional coatings (Ref 1), and their use is expected to expand. The need for understanding the arc behavior and process control led to intensive modeling works over the course of many years (see e.g., (Ref 2-4) and references therein).

The models of plasma spray torches are based on a multiphysics description. They apply in general a set of magnetohydrodynamic (MHD) equations that connect the conservation of mass, momentum, and energy of the plasma treated as a fluid with the electric and magnetic field. A variety of models comprise a two- and a threedimensional consideration, steady-state, and time-dependent conditions, equilibrium and non-equilibrium treatment of the arc plasma, given distributions of temperature and current density on the cathode tip or accounting for properties of the near-electrode regions. Three-dimensional and time-dependent models enable the description of the restrike mode of arc attachment on the anode (Ref 2). Nonequilibrium models account for the interaction of the plasma with the cold gas and deviations from equilibrium (thermal and/or chemical) in the arc plasma (Ref 5, 6).

First models unifying the region of the arc plasma and the electrodes in the same computational domain go back to the 1990s. In some of them (Ref 7), the current density is set on the cathode base as the total current over the cross section area. Such models were presented for direct current (DC) plasma spray torch (Ref 8,9$)$ and are currently used in some modeling works on welding arcs (Ref 10). The electric coupling of the plasma and the electrode in these models occurs through an interface. A current density along the cathode surface is obtained, but achieving a 
proper arc attachment is problematic. An artificial restriction of the current-collecting part of the cathode surface is needed to obtain a current density distribution concentrated at the cathode tip, to simulate the thermionic behavior of the arc root (Ref 11) and to obtain plasma temperatures that agree with experiments (Ref 12). In other models, a current density profile (in general Gaussian-like) at the cathode tip is imposed to match measured data. Therefore, there is no electrical coupling of the cathode and the plasma, but a boundary condition is provided for the electric part of the MHD model. The thermal coupling in the models of both groups accounts for a heat flux to the cathode including contributions from ion recombination, thermionic emission, and black body radiation. However, these models do not necessarily provide the profiles, which are consistent with the properties of the boundary layer adjacent to the electrode. In order to evaluate the appreciable amount of energy deposited in the cathode boundary layer (Ref 13), the models have to ensure both electrical and thermal coupling of the arc plasma and the cathode. Such a coupling, not used yet in a published modeling of DC plasma spray torches, can be performed in a unidirectional (Ref 4, 14-16) or bidirectional (Ref 17, 18) manner in the framework of equilibrium or non-equilibrium models.

In-house numerical codes (Ref 5,8$)$ as well as models based on open-source software (Ref 6) and commercial platforms such as ANSYS Fluent (Ref 19, 20) among others have been developed. The models are being continuously further developed and utilized to meet certain requirements for a more realistic physical picture and understanding of the processes. As an example, a special attention has been paid recently on the effect of the boundary conditions for the equation for the magnetic field on the overall solution (Ref 21) and, respectively, the properties of a commercial plasma spray torch.

Time-dependent or steady-state solutions can also be obtained by using the commercial computation platform COMSOL Multiphysics (Ref 22). This platform provides the opportunity to combine various physical processes, such as the transport of particles and energy with electromagnetics, as needed for plasma spray modeling and allows customizing of the governing equations. Furthermore, it offers important features for generating geometries and computational meshes, a discretization of the system of partial differential equations using the finite element method for the space variables, powerful solvers that are fully parallelized and make use of multicore computing, as well as a powerful visualization and a post-processing of the results obtained. Advanced models of electric arcs have been developed on this platform (Ref 17) and successfully established as powerful tools capable of predicting the arc plasma properties.
In the present work, we consider a two-dimensional and stationary model of a direct current plasma spray torch developed on the computational platform COMSOL Multiphysics to describe a steady operating mode. The model couples both thermally and electrically the arc plasma column in the state of local thermodynamic equilibrium (LTE) with the electrodes. We focus on two features. First, we pay attention to the coupling of the plasma to the refractory cathode, which allows us to obtain the voltage drop in the cathode boundary layer and more realistic profiles of the temperature and the current density on the cathode surface. These profiles are important to the formation of the arc plasma jet. Second, we focus on the solution of the plasma flow. The computational platform provides the opportunity to apply different approaches for the numerical solution of a compressible laminar plasma flow in dependence on the flow conditions. These approaches are denoted as "low Mach number" and "high Mach number" with respect to the ratio of the magnitude of the fluid velocity to the speed of sound $(\mathrm{Ma}=|\boldsymbol{u}| / a)$, which is called the Mach number. Results obtained by the two approaches are compared in order to explore their appropriateness for various flow rates and current values.

The paper is organized as follows. The plasma spray torch, for which the studies are carried out, is presented in the "Experimental equipment" section. In the "Computational method" section, we give a general description of the model and consider the coupling of the plasma to the electrodes, and the boundary conditions set in the models for the low and high Mach number models. Results of the models and experimental findings are given and discussed in the "Results and discussion for the LTE plasma" section. Concluding remarks are summarized in the "Conclusions" section.

\section{Experimental Equipment}

The plasma spray torch considered in the present study is the commercial device Oerlikon Metco F4MB-XL (Ref 23) (Fig. 1a). This is characterized by a single-cathode and a single-anode arrangement. The WL10 cathode by Plansee is made of lanthanated tungsten (Ref 24) and sticks to a copper holder. The nozzle is cylindrically symmetric and serves as anode. Its cylindrical fragment is partly made of tungsten (Fig. 1b). The cathode base and the nozzle are water-cooled. The gas is fed between the cathode and the anode. While the attachment at the cathode is well positioned at the cathode tip and the attachment area extends with the increase in the electric current, the attachment at the anode can move in azimuthal and axial directions with the variation of the flow rate and the electric current to adjust according to the balance of the Lorenz and the drag 

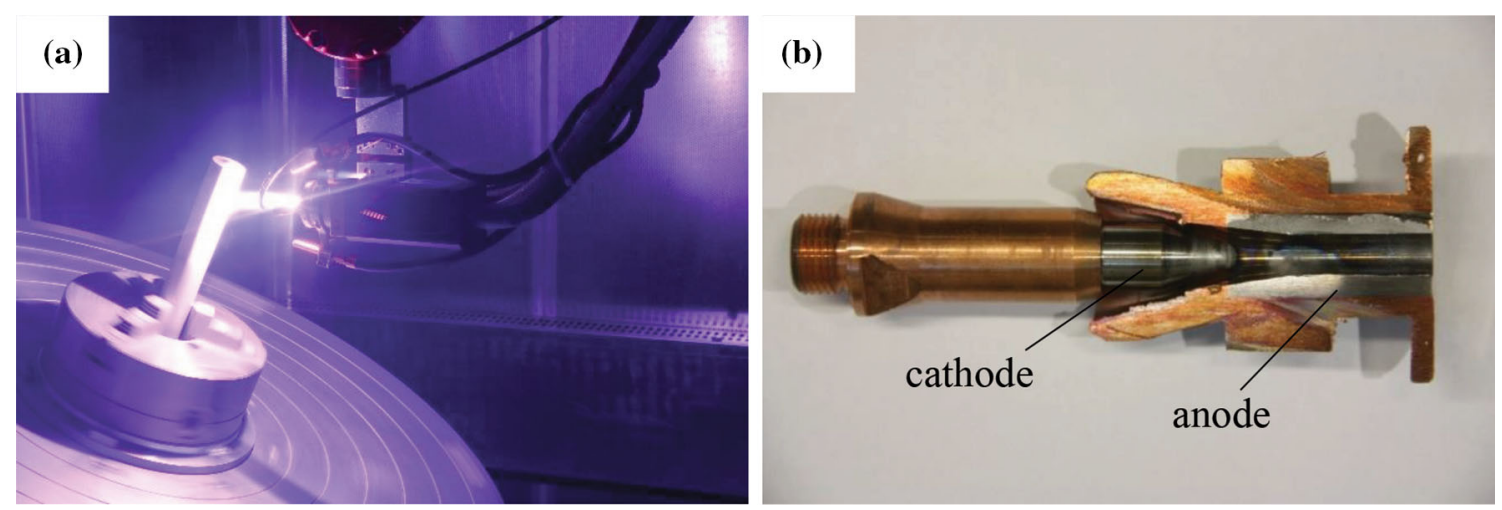

Fig. 1 (a) A general view of the plasma spray torch and the generated plasma jet. (b) The electrodes of the plasma spray torch

forces. The traces are visible by the tarnished color in Fig. 1b. The torch is operated in pure argon and mixtures of argon with hydrogen or nitrogen with typical flow rates of 40 to 80 NLPM and DC current of 600 to $800 \mathrm{~A}$.

The stable operation of plasma spray torches is of central importance in their design (Ref 25). The control of the arc current and the gas flow rate is essential for the arc stability. The latter is mainly related to the stability of the anode attachment (Ref 26). A steady operation mode characterized by very low fluctuations of the arc voltage can be established in operation with pure argon (Ref $25,26)$. Admixtures of molecular gases $\left(\mathrm{H}_{2}, \mathrm{~N}_{2}\right)$ typically lead to the restrike or takeover modes of the anode attachment. Furthermore, high flow rates can lead to an increase in the thickness of the anode boundary layer and favor stronger voltage fluctuations (Ref 27). In the present study, a steady operating mode of the torch with a straight flow and fresh electrodes is considered. The operating conditions are shown in Fig. 2, where the recorded power, voltage, current, and flow rate are plotted over a time interval of 1 hour with a time step of $1 \mathrm{~s}$. The operation mode was sustained, as the current was held constant by adjusting the applied voltage. The conditions are a flow rate of argon (40.0 \pm 0.3$)$ NLPM, an electric current of $(599.10 \pm 0.15)$ A, a voltage of $(32.3 \pm 0.2) \mathrm{V}$, and an electric power of $(19.20 \pm 0.12) \mathrm{kW}$. The relative low sampling rate is given by the software of the process control center and does not allow for fully excluding the presence of fluctuations with typical times in the millisecond range as demonstrated by Duan et al. (Ref 26). However, instabilities of low frequency do not occur. The operating mode remains steady also at the higher flow rates and currents. Deviations from the steady values occur during the start and the end phase of operation, which, however, are out of scope of the present work. The stable values of the measured voltage (a relative deviation of $0.6 \%$ ) indicate a stable root at the anode in the time window under consideration. The experiments are performed with fresh electrodes to prevent instabilities caused by erosion due to long time of operation.

\section{Computational method}

We consider the real inner geometry of the plasma spray torch F4MB-XL (Oerlikon Metco) (Fig. 1). A schematic of the computational domain is shown in Fig. 3.

The modeling is aimed to describe the steady operating mode of the plasma spray torch. The axial symmetry of the torch arrangement along with the observed stable behavior of the operating conditions in argon (Fig. 2) offers the opportunity to set up the model as two-dimensional, axisymmetric, and stationary. In addition, the plasma bulk is considered to be at conditions close to LTE. It is known that deviations from LTE occur in the near-electrode regions and walls, near the inlet, and to a lesser extent in the plasma bulk. Most important are the non-equilibrium near-electrode regions, in particular the cathode region (Ref 13). The thickness of the near-electrode regions decreases, and the deviations from LTE in the plasma bulk progressively decrease with the increase in the arc current. The assumption of LTE in the present work is justified by the relative high currents at which the torch is operated.

The modeling of the DC plasma spray torch combines a steady-state MHD description of LTE arc plasma in axisymmetric configuration, the current and heat transfer in the electrodes, and the interaction between the plasma and the electrodes.

It comprises the cathode, the anode, and the region between them, where the plasma is generated. The cylindrical part of the cathode has a radius of $4.9 \mathrm{~mm}$, and the rounded cathode tip has a radius of $1.9 \mathrm{~mm}$. The cylindrical part of the nozzle has an inner radius of $3 \mathrm{~mm}$ and a length of $20 \mathrm{~mm}$. The length of the gas inlet A'B is $5.1 \mathrm{~mm}$.

The combined model of the plasma spray torch consists of two parts: a submodel of the LTE plasma with the nozzle 

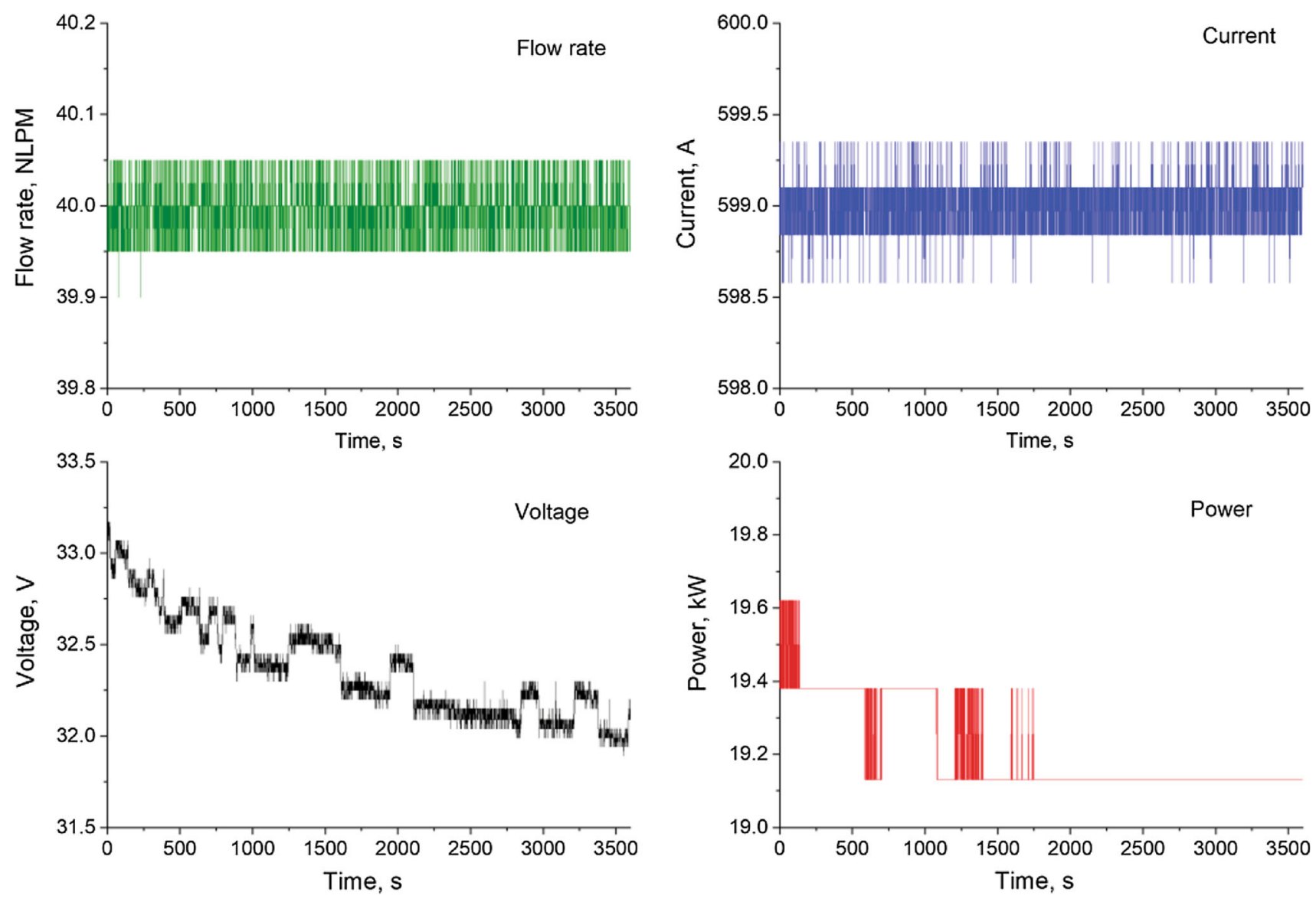

Fig. 2 Recorded operation conditions of the plasma spray torch

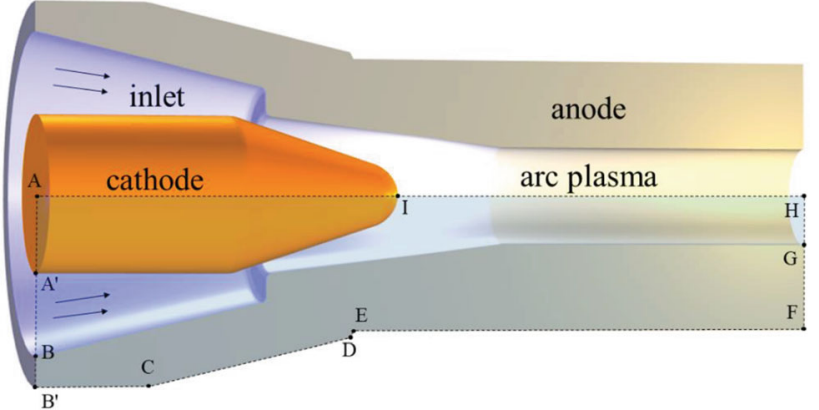

Fig. 3 A schematic view of the torch geometry and the computational domain

and a submodel of the cathode with the non-equilibrium cathode boundary layer, which provides boundary conditions for the first submodel. These submodels and their coupling are considered below.

\section{Governing equations of the MHD model}

The MHD two-dimensional axisymmetric model involves the Navier-Stokes equations for the conservation of mass, momentum, and energy of the gas flow and the Maxwell equations for the electromagnetic field in their wellestablished form for arc plasma (Ref 20) and plasma torch modeling (Ref 3, 4, 21). The plasma generated in the torch is assumed to behave like a fluid in the state of local thermodynamic equilibrium and optically thin. The flow is laminar and compressible. Operation in argon is considered for the present study. The governing equations are written as follows:

- Mass continuity

$$
\nabla \cdot(\rho u)=0
$$

- Momentum conservation

$$
\rho(\boldsymbol{u} \cdot \nabla) \boldsymbol{u}=\nabla \cdot(-p \hat{I}+\hat{\tau})+\boldsymbol{F}_{L}
$$

- Energy conservation

$$
\rho C_{p} \nabla T=\nabla \cdot(k \nabla T)+Q_{J}+Q_{e}+Q_{p}-Q_{r}
$$

- Current continuity and Ohm's law

$\nabla \cdot \boldsymbol{j}=0, \boldsymbol{j}=\sigma(\boldsymbol{E}+\boldsymbol{u} \times \boldsymbol{B})$

- Maxwell equation 


$$
\nabla \times(\nabla \times \boldsymbol{A})=\mu_{0} \boldsymbol{j}
$$

These equations contain the following notations in the order of their appearance: nabla operator $(\nabla)$, mass density $(\rho)$, velocity of the fluid $(\boldsymbol{u})$, gas pressure $(p)$, identity matrix $(I)$, stress tensor for Newtonian fluid $(\hat{\tau})$, Lorentz force $\left(\boldsymbol{F}_{L}\right)$, specific heat at constant pressure $\left(C_{p}\right)$, gas temperature $(T)$, thermal conductivity $(\kappa)$, Joule heating $\left(Q_{J}\right)$, heating due to transport of electron enthalpy $\left(Q_{e}\right)$, pressure work $\left(Q_{p}\right)$, radiative losses $\left(Q_{r}\right)$, electric current density $(\boldsymbol{j})$, electrical conductivity $(\sigma)$, electric field $(\boldsymbol{E})$, self-induced magnetic field $(\boldsymbol{B}=\nabla \times \boldsymbol{A})$, the permeability of free space $\left(\mu_{0}\right)$, and magnetic vector potential $(\boldsymbol{A})$.

The Navier-Stokes equations 1-3 and the electromagnetic equations 4-5 are coupled to each other through the Lorentz force $\left(F_{L}=\boldsymbol{j} \times \boldsymbol{B}\right)$, the Joule heating $\left(Q_{J}=\boldsymbol{j} \cdot \boldsymbol{E}\right)$, the transport of electron enthalpy $Q_{e}=\frac{5 k_{B}}{2 e} \boldsymbol{j} \cdot \nabla T$, and the induced current density $(\sigma \boldsymbol{u} \times \boldsymbol{B})$. Here, $k_{B}$ denotes the Boltzmann constant and $e$ is the elementary charge. We notice that the term $Q_{e}$ is taken into account in the LTE plasma bulk, where by definition $T=T_{e}$, i.e., an overestimation of the temperature gradient due to steeper gradient of the temperature of heavy species $(T)$ than that of the electron temperature $\left(T_{e}\right)$ does not occur.

Although both the low and high Mach number approaches consider Eq 1-5, their solution procedures are partly different. In the low Mach number approach, the laminar flow interface of COMSOL Multiphysics (Ref 22) employs Eq 1 and 2 and is applied for compressible flow at Mach numbers typically below 0.3 to compute the velocity and pressure. The fluid density does not depend on pressure but on temperature. Equation 1 and 2 is coupled with Eq 3 to 5 . The high Mach number approach employs the high Mach number flow interface of COMSOL Multiphysics (Ref 22) that combines the heat transfer Eq 3 with the laminar flow Eq 1 and 2. The use of this interface enables a two-way coupling between the flow and the heat equations so that the same definition of density is used, which can therefore be a function of both pressure and temperature. The coupling with Equation 4 and 5 is the same as in the low Mach number model.

Notice that a reference pressure of 1 atm $(101.325 \mathrm{kPa})$ is considered for the solution of the fluid equations. The equilibrium thermodynamic and transport properties of argon are considered as functions of the absolute pressure and the temperature and are prepared as look- up tables. The calculated data for a pressure of $1 \mathrm{~atm}$ is benchmarked against published data by A. B. Murphy (Ref 28,29) and data obtained with the T\&T tool by B. Pateyron (Ref 30 ). The radiative losses are considered in terms of the net emission coefficient with data by Menart and Malik (Ref 31). Since the range of absolute pressure is limited between
1 and $1.5 \mathrm{~atm}$, the net emission coefficient is linearly scaled up for a pressure higher than $1 \mathrm{~atm}$.

\section{Heat and Current Transfer in the Electrodes}

The equations of heat and current transfer in the electrodes are solved for the temperature $T_{s}$ and the electric potential $\varphi_{\mathrm{s}}$ in the solid bodies of the electrodes, i.e.,

$-\nabla \cdot\left(k_{\mathrm{s}} \nabla T_{s}\right)=\boldsymbol{j}_{s} \cdot \boldsymbol{E}_{s}$

$\nabla \cdot \boldsymbol{j}_{s}=0, \boldsymbol{j}_{s}=-\sigma_{s} \nabla \varphi_{s}$

where $\kappa_{\mathrm{s}}$ and $\sigma_{\mathrm{s}}$ represent, respectively, the temperaturedependent thermal and electrical conductivity of the electrode materials (Ref 32-36), $\boldsymbol{j}_{\mathrm{s}}$ is the current density, $\boldsymbol{E}_{\mathrm{s}}=$ $-\nabla \varphi_{\mathrm{s}}$ is the electric field.

\section{Arc-electrode Interaction}

Deviations from LTE conditions occur in thin regions between the core plasma and the electrodes, which have to ensure the current transfer. In particular, the cathode region is of central importance where a large amount of energy is deposited (Ref 13). A consistent coupling of the solutions of Eq 1-5 (MHD model) and Eq 6-7 (cathode and its boundary layer) provides a self-consistent solution for the plasma spray torch avoiding empirical input.

A schematic of a unidirectional coupling between the cathode and the LTE plasma is shown in Fig. 4. The coupling is realized as follows.

Prior to the simulations, the non-equilibrium boundary layer (BL) between the cathode and the plasma is considered, which comprises a region of space charge adjacent to the cathode, a pre-sheath (ionization layer and a layer of thermal relaxation). This layer is thin and not included in the computational domain, but its properties are taken into account applying the model by Benilov et al. (Ref 37$)$. According to this model, the space charge sheath is treated as collisionless for ions and electrons. The current carriers are electrons emitted from the cathode due to field-enhanced thermionic emission, and counter-diffusing electrons and ions from the plasma. The ions are assumed to reach the Bohm velocity at the sheath edge and to recombine at the cathode surface. The balance of energy and electric current density are solved for various $\left(T_{w}\right.$, $U$ ) values given the pressure, the work function of the cathode material, and a pre-calculated plasma composition for given temperatures of heavy particles and electrons at a given pressure. The properties of the non-equilibrium boundary layer such as temperature of heavy particles and electrons, species number densities, current density, voltage drops over the space charge sheath and pre-sheath, density of energy fluxes are used to express the heat flux to 
Fig. 4 Schematics of the thermal and electric coupling of the cathode and the LTE bulk plasma

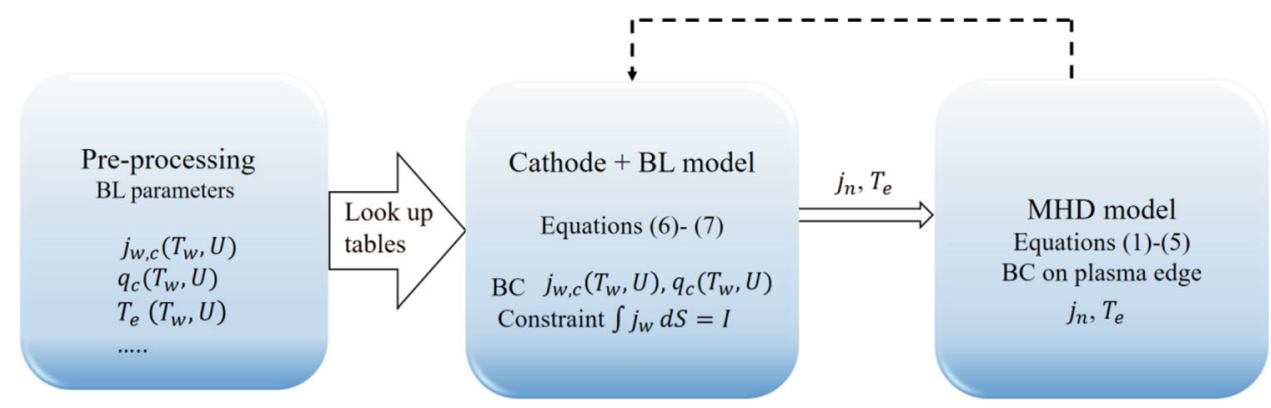

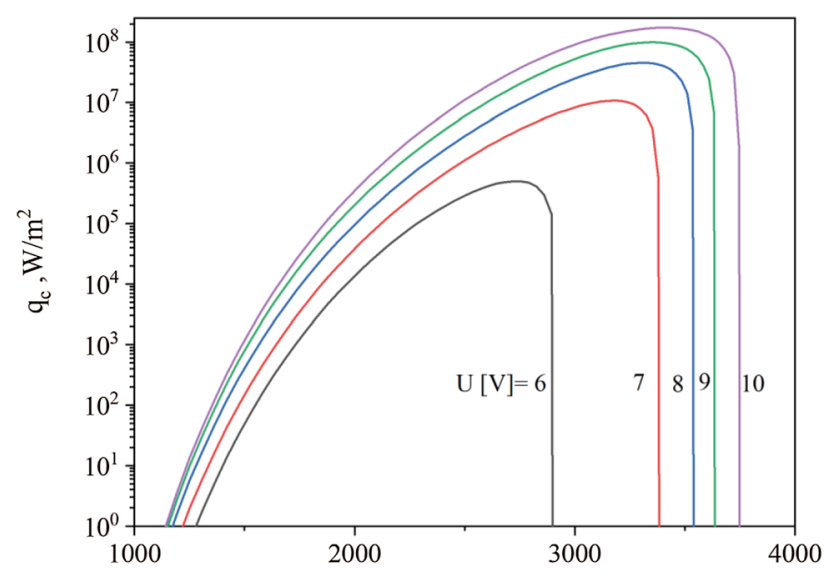

(a)

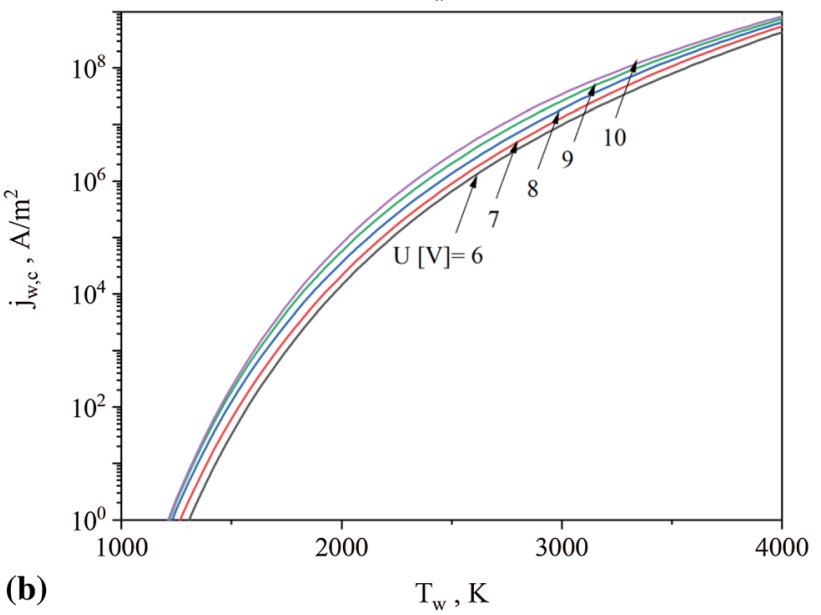

Fig. 5 The transfer functions: (a) $q_{c}\left(T_{w}, U\right)$ and (b) $j_{w, c}\left(T_{w}, U\right)$ obtained for W-La cathode (the work function $2.7 \mathrm{eV}$, the Richardson constant $0.08 \bullet 10^{6} \mathrm{~A} /\left(\mathrm{m}^{2} \mathrm{~K}^{2}\right)(\operatorname{Ref} 38)$

the cathode surface $q_{c}$ and the normal current density at the cathode surface $j_{w, c}$ as functions of the surface temperature of the cathode $T_{w}$ and the voltage drop in the boundary layer $U$. These are the so-called transfer functions, which are supplied to the combined model as two-dimensional arrays $j_{w, c}\left(T_{w}, U\right)$ and $q_{c}\left(T_{w}, U\right)$. The transfer functions are shown in Fig. 5 for values of the temperature of the cathode surface between 1000 and $4000 \mathrm{~K}$ and the voltage drop in the cathode boundary layer between 6 and $10 \mathrm{~V}$. A more complete data set can be found in the database (Ref 38).

As a first part of the combined model, the current and heat transfer in the cathode are solved according to the method of nonlinear surface heating (Ref 40, 41). According to this method, the transfer functions $j_{w, c}\left(T_{w}, U\right)$ and $q_{c}\left(T_{w}, U\right)$ are set as boundary conditions to Eq 6 and 7 at the edge to the LTE plasma (I A' in Fig. 3). Additionally, cooling of the solid due to black body radiation (a term $\varepsilon\left(T_{s}\right) \sigma_{S B} T_{s}^{4}$ with $\varepsilon(T)$ being the temperature-dependent emissivity of tungsten (Ref 32) and $\sigma_{S B}$ being the StefanBoltzmann constant) is taken into account. Emission and absorption of plasma radiation are not considered in the energy balance of the cathode. On the base of the cathode (AA'), a temperature of $300 \mathrm{~K}$ (the cathode is watercooled) and zero potential are set. The computation starts with an initial guess of the values $T_{w}$ and $U$ (e.g., $2000 \mathrm{~K}$ and $11 \mathrm{~V}$, respectively) for which the corresponding values of $j_{w, c}$ and $q_{c}$ are read from the lookup tables. The solution of Eq 6 and 7 provides the current density and the temperature in the cathode. Additionally, a global equation is formulated as

$\int_{s} j_{w, c}\left(T_{w}, U\right) d s-I=0$

and solved iteratively along with $\mathrm{Eq} 6$ and 7, until the target current $I$ collected on the cathode is reached. The solution provides the value of the voltage drop in the cathode boundary layer $U$, which is considered constant along the cathode surface, the distributions of the temperature and the normal current density $\left(j_{n}\right)$ on the cathode surface, as well as the electron temperature $\left(T_{e}\right)$ in the nonequilibrium boundary layer adjacent to the cathode. These quantities are used as boundary conditions for the MHD submodel in the next step.

The electric and thermal coupling of the cathode and the LTE bulk plasma considered so far is unidirectional. A bidirectional coupling as realized in Ref 17 and 18 could return values for the electric potential obtained along the edge IA' from the MHD model to the first submodel as indicated by the dash line in Fig. 4. In this case, the voltage drop in the boundary layer would not be constant along the 
edge and the distributions of current density and temperature along the cathode could change. A more diffuse arc attachment on the cathode would reduce the maximum current density and temperature and affect the predicted flow velocity close to the cathode. A bidirectional coupling is not applied in the present model of the plasma spray torch and will be followed in future works.

Results from the submodel of the cathode and its boundary layer are presented in Fig. 6 and 7. Figure 6 shows the predicted voltage drop in the cathode boundary layer for current between 100 and $800 \mathrm{~A}$. The results show that the voltage drop gradually drops from about $16 \mathrm{~V}$ at a current value of $100 \mathrm{~A}$ down to about $8 \mathrm{~V}$ at a current of 800 A. Given a total arc voltage of about $32 \mathrm{~V}$ (800 A, 40 NLPM), the voltage drop in the cathode boundary layer represents a substantial part of the total value. This shows the need for the submodel of the cathode and its boundary layer.

Figure 7 shows the distributions of (a) the temperature $T_{w}$, (b) the normal current density $j_{w}$ on the cathode surface, and (c) the electron temperature in the boundary layer $\mathrm{T}_{e}$ as a function of the distance along the cathode surface. This distance is measured along the line IA' (see Fig. 3) starting from the center I of the cathode tip and moving toward its base A'. The results are shown for currents of 300, 600, and $800 \mathrm{~A}$. The values 600 and $800 \mathrm{~A}$ are typical for the operation of the plasma spray torch. Notice that the extent of the flat parts of the distributions is about $1 \mathrm{~mm}$. Toward the cathode base, the values progressively decrease before the end of the conical part of the cathode. Electric current is collected even in the periphery of the cathode. The cathode temperature (Fig 7a), the current density (Fig $7 b)$ in the center of the cathode tip, and the electron temperature at the center of the edge to the LTE bulk plasma (Fig 7c) are highest for a current value of $300 \mathrm{~A}$. The values decrease with the increase in the total current.

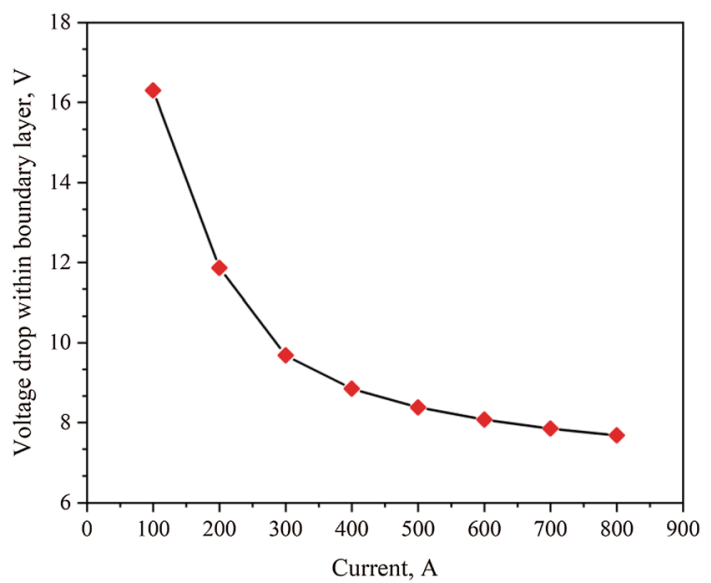

Fig. 6 Voltage drop in the cathode boundary layer as a function of the arc current
Considering a distance of $1 \mathrm{~mm}$ from the center of the cathode tip along the cathode surface, the corresponding area of the cathode surface collects about $90 \%, 46 \%$, and $30 \%$ of the total current for, respectively, 300, 600, and 800 A. Hence, the attachment area increases with the increase in the current. The decrease in the current density with the increase in the total current corresponds to a decrease in the voltage drop in the boundary layer (Fig. 6) and the heat flux $\mathrm{q}_{\mathrm{c}}$ (Fig. 5). As a result, the temperature at the center of the cathode decreases. The lesser power in the boundary layer leads to lower electron temperature at the edge to the LTE plasma.

The method of nonlinear surface heating has been considered as inapplicable to the arc-anode interaction (Ref 42). Usual practice in considering the arc-anode interaction in LTE models of the core plasma is to apply a heat flux to the anode, which is given by the condensation of electrons (Ref 43,44$)$, i.e., $q_{\mathrm{a}}=|j| \phi_{\mathrm{a}}$. Here, it is assumed that the ion current density is negligible so that the electron current density equals the total one. $\Phi_{\mathrm{a}}$ is the work function of the anode material. Recent work (Ref 42) has presented results of unified modeling of the anode region of electric arcs in argon among other gases under atmospheric and higher pressure. It has been suggested that the heat flux to the anode can be considered as independent of the anode temperature and can be expressed as the product of the

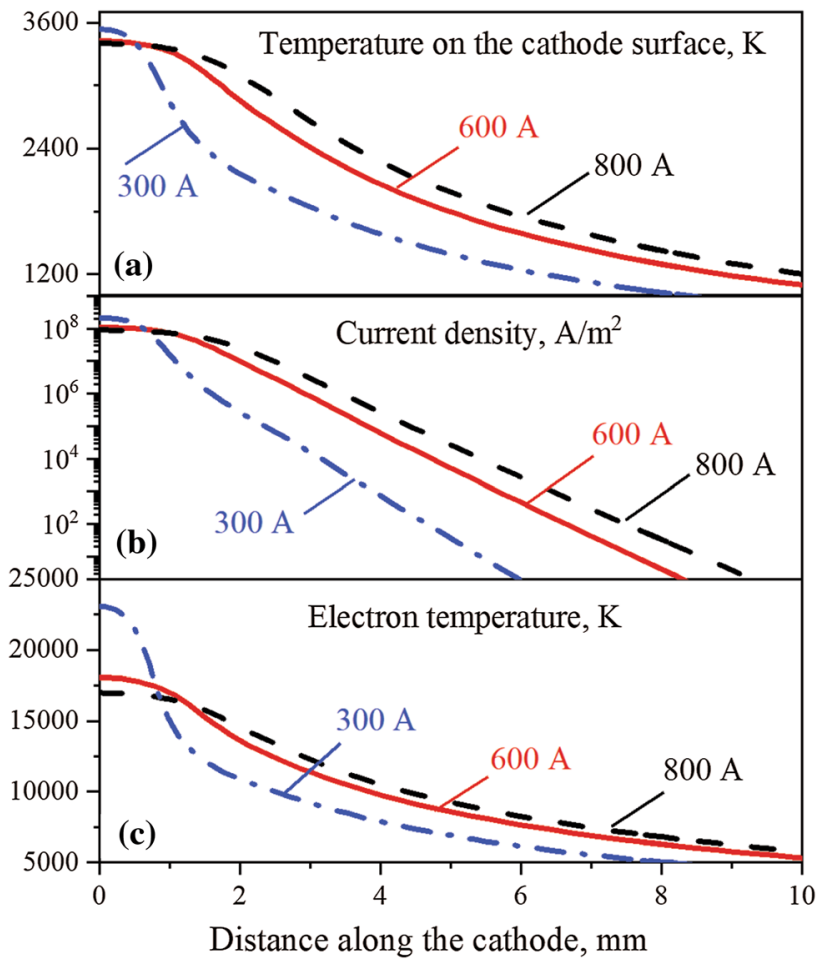

Fig. 7 Distributions along the cathode surface for current values of $300 \mathrm{~A}, 600 \mathrm{~A}$ and $800 \mathrm{~A}$ : (a) cathode temperature $T_{w}$, (b) current density $j_{w, c}$, and (c) electron temperature in the cathode boundary layer 
current density and "anode heating voltage." Its value has been evaluated as $U_{\mathrm{h}}=6.1 \mathrm{~V}$ for arcs in atmospheric pressure argon over a wide range of values of the current density. This value exceeds that of $\phi_{a}$ and will lead to higher values of $q_{a}$. In the present work, we apply the latter result and consider $q_{a}=|j| U_{\mathrm{h}}$, which gives an upper limit of the anode heating. In addition, a cooling of the anode due to black body radiation is taken into account. Therefore, the additional heat flux to the anode reads

$q_{a}^{a d}=q_{a}-\varepsilon(T) \sigma_{S B} T^{4}$

Since no model of the anode boundary layer (like that for the cathode) is applied so far, the current transfer to the anode is enabled by setting a low limit of the electrical conductivity $(100 \mathrm{~S} / \mathrm{m})$ in the vicinity of the anode. Such simplified treatment has been suggested by V. Nemchinsky (Ref 45) in a model of arc re-attachment on the anode.

We notice that due to the two-dimensionality and the axial symmetry of the model, the arc attachment on the electrodes, in particular the attachment on the anode, spreads on effectively larger surface than in the real threedimensional geometry. While in the real case the attachment can occur as a localized spot, the axisymmetric solution imposes a band around the axis. Therefore, the thermal load on the anode rather represents its low limit.

\section{Boundary Conditions}

Some of the boundary conditions have been already considered in the previous part that is concerned with the arcelectrode interaction. The boundary conditions applied to solve the set of governing Eq 1-5 are summarized in Table 1 .

The Navier-Stokes equations for a laminar and compressible fluid (1)-(3) are solved in the frameworks of the two numerical approaches (in terms of stabilization and boundary conditions) that are implemented in COMSOL Multiphysics. They are abbreviated as "Low Ma" and
"High Ma" in Table 1. For details, the reader may turn to the corresponding documentation ( $\operatorname{Ref} 22)$ and the original literature used by the developers (Ref 46-49). According to developers' information, the stabilization and boundary conditions for the compressible formulation for the laminar flow interface are not designed for handling Mach numbers higher than approximately 0.3 . Therefore, the boundary conditions at the inlet boundary (A'B ) for the two approaches are different. While in the high Mach number model three values $\left(p_{0 \text {,stat }}, \mathrm{Ma}_{0}\right.$, and $\left.T_{0 \text {,stat }}\right)$ are set (Table 1$)$, a mass flow rate $(\dot{m})$ and temperature $\left(T_{0}\right)$ are set in the low Mach number model. In order to ensure that the same mass flow rate is considered in both models, the values of $p_{O \text {,stat }}$ and $\mathrm{Ma}_{0}$ are adjusted.

The gas flow rate measured in the experiments is given in units of "NLPM," where "N" stands for normal temperature $(293.15 \mathrm{~K})$ and pressure $(101.325 \mathrm{kPa})$ (Ref 50). The corresponding mass rate of argon is set on the inlet (A'B) for the low Mach number model.

The high Mach number approach assumes that the fluid behaves like an ideal gas in order to formulate consistent inlet and outlet boundary conditions (Ref 47). The flow conditions are monitored on the boundary. Since the flow properties are coupled, a characteristics-based inlet is considered. On the inlet A'B, the pressure, the Mach number, and the temperature are defined, from which the density is calculated based on the ideal gas law.

Pressure at infinity is set for the outlet (HG) in both cases. A non-slip boundary condition is applied along the cathode surface (A'I) and the nozzle surface (BG).

A temperature of $300 \mathrm{~K}$ is set on the inlet ( $\mathrm{A}^{\prime} \mathrm{B}$ ) for both cases. The profile of the electron temperature $T e$ obtained from the solution of the submodel of the cathode and its boundary layer is set along the cathode surface (A'I). A boundary heat flux $q_{a}^{a d d}(\mathrm{Eq} 9)$ is set on the anode surface (BG) additionally to the conductive heat flux occurring between the plasma and the anode. A forced convective cooling $\left(q_{c o n v}=h\left(T_{a m b}-T\right)\right.$ with a heat loss coefficient
Table 1 The boundary conditions utilized in the model of the plasma spray torch

\begin{tabular}{|c|c|c|c|c|c|c|}
\hline $\begin{array}{l}\text { Equation } \\
\text { Boundary }\end{array}$ & (1) & (2) & (3) & (4) & (5) & Remark \\
\hline$A^{\prime} B$ & $p_{0, \text { stat }}=1.38 \mathrm{~atm}$ & $\mathrm{Ma}_{0}$ & $T_{0, \text { stat }}=300 \mathrm{~K}$ & $\boldsymbol{n} \bullet \boldsymbol{j}=0$ & $\boldsymbol{n} \times \boldsymbol{A}=0$ & High Ma \\
\hline$A^{\prime} B$ & $\dot{m}=1.189 \times 10^{-3} \mathrm{~kg} / \mathrm{s}$ & $\ldots$ & $T_{0}=300 \mathrm{~K}$ & $\boldsymbol{n} \bullet \boldsymbol{j}=0$ & $\boldsymbol{n} \times \boldsymbol{A}=0$ & Low Ma \\
\hline $\mathrm{BB}^{\prime}$ & $\ldots$ & $\ldots$ & $-\boldsymbol{n} \bullet \boldsymbol{q}=0$ & $\boldsymbol{n} \bullet \boldsymbol{j}=0$ & $\boldsymbol{n} \times \boldsymbol{A}=0$ & Both \\
\hline $\mathrm{B}^{\prime} \mathrm{CDEF}$ & $\ldots$ & $\ldots$ & $q_{c o n v}$ & $\mathrm{~V}=0$ & $\boldsymbol{n} \times \boldsymbol{A}=0$ & Both \\
\hline FG & $\ldots$ & $\ldots$ & $-\boldsymbol{n} \bullet \boldsymbol{q}=0$ & $\boldsymbol{n} \bullet \boldsymbol{j}=0$ & $\boldsymbol{n} \times \boldsymbol{A}=0$ & Both \\
\hline GH & $p=1 \mathrm{~atm}$ & $\ldots$ & $-\boldsymbol{n} \bullet \boldsymbol{q}=0$ & $\boldsymbol{n} \bullet \boldsymbol{j}=0$ & $\boldsymbol{n} \times \boldsymbol{A}=0$ & Both \\
\hline A’I & $\ldots$ & $\boldsymbol{u}=0$ & $T_{e}(s)$ & $j_{w}(s)$ & $\ldots$ & Both \\
\hline BG & $\ldots$ & $\boldsymbol{u}=0$ & $q_{a}^{a d d}$ & $\ldots$ & $\cdots$ & Both \\
\hline
\end{tabular}

Remarks: The subscript "stat" denotes a static parameter. The mass rate value corresponds to a flow rate of 40 NLPM. 


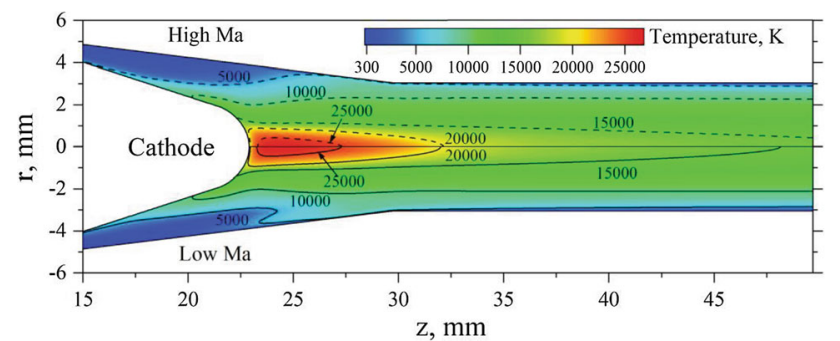

Fig. 8 The temperature field from the low and the high Mach number models. Current 600 A, gas flow rate of argon 40 NLPM

$h=10^{4} \mathrm{~W} /\left(\mathrm{m}^{2} \mathrm{~K}\right)(\operatorname{Ref} 51)$ and $T_{a m b}=500 \mathrm{~K}$ is applied for the water-cooled outer surface of the nozzle (B'CDEF). Zero heat flux is set on the boundaries BB', FG, and GH.

For Eq 4, a normal current density $j_{w}(s)$ is set along the cathode surface (A'I), which is obtained from the solution of the submodel of the cathode and its boundary layer. The anode is grounded. (The electric potential is set to zero on (B'CDEF).) The other boundaries are electrically insulated.

For Eq 5, "null flux" boundary condition is set for the vector potential. It has been reported in Ref 52 that the vector potential formulation for the calculation of the magnetic field implemented in COMSOL Multiphysics applying the finite elements approach and the gauge fixing for "null flux" and "null value" are in a perfect agreement with the analytical solution for test cases. We notice that the calculation of the magnetic field is performed in the entire computational domain (B'FHA) including the cathode, accounting for the current flowing in the cathode as it is done in Ref 21 .

\section{Results and Discussion for the LTE Plasma}

Results are obtained for the operation of the torch in argon with currents of 600 and $800 \mathrm{~A}$ and flow rates of 40,60, and 80 NLPM. The calculations are performed for the low and the high Mach number cases. The two-dimensional and axis-symmetric computational domain is considered with about 23500 mesh elements. The typical computational time to reach a converged solution on a computer with two sockets and a total of 16 cores at $3.3 \mathrm{GHz}$ is about $5 \mathrm{~min}$. The data that support the results of this study are openly available in INPTDAT (Ref 39).

Figure 8, 9, 10, and 11 shows the two-dimensional distributions of, respectively, the predicted temperature, velocity fields, current density, and electric potential obtained with the low and the high Mach number approaches for a current of $600 \mathrm{~A}$ and a flow rate of 40 NLPM. The temperature field in the inner space of the plasma torch is plotted by five isotherms with an interval of $5000 \mathrm{~K}$ (Fig. 8). In both the low and high Mach number models, the

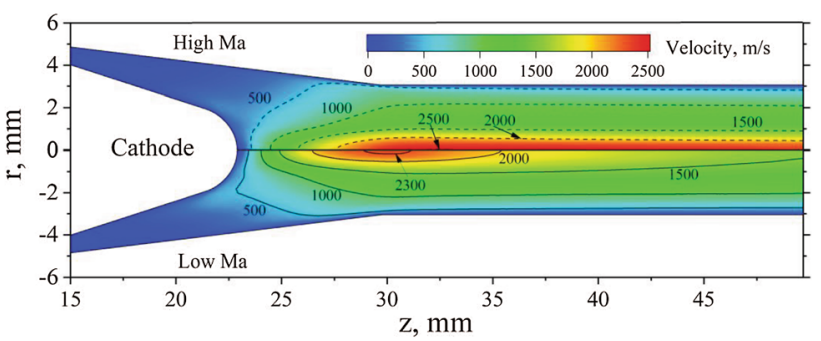

Fig. 9 The velocity field from the low and the high Mach number models (the working conditions are the same as in Fig. 8)

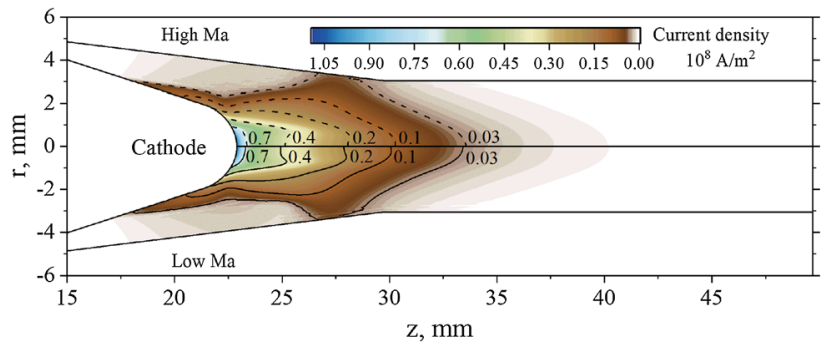

Fig. 10 The current density from the low and the high Mach number models (the working conditions are the same as in Fig. 8)

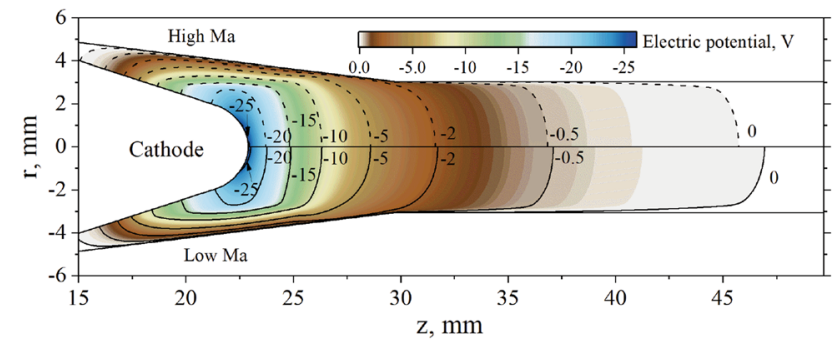

Fig. 11 The electric potential from the low and the high Mach number models (the working conditions are the same as in Fig. 8)

plasma temperature reaches a peak value of about $26400 \mathrm{~K}$ on the torch axis in the vicinity of the cathode tip, where the current density and the Joule heating are the highest. The temperature gradually decreases toward the outlet. In the high Mach number model, the axial extent of the isotherms is only a bit larger for temperatures of $20000 \mathrm{~K}$ and above. But the $15000 \mathrm{~K}$ isotherm ends $2 \mathrm{~mm}$ before the outlet in the low Mach case, while the corresponding isotherm in the high Mach number case reaches the outlet.

Differences are more pronounced in the corresponding velocity fields (Fig. 9). Maximum velocity in the low Mach number model of about $2340 \mathrm{~m} / \mathrm{s}$ is reached at the axial distance of about $30 \mathrm{~mm}$, while in the high Mach number model a value of about $2500 \mathrm{~m} / \mathrm{s}$ is obtained at the axial distance $\mathrm{z}=32 \mathrm{~mm}$. In both models, the contour at $1500 \mathrm{~m} / \mathrm{s}$ extends beyond the outlet. However, a velocity of $2000 \mathrm{~m} / \mathrm{s}$ at the outlet is obtained in the high Mach number model, while the contour at $2000 \mathrm{~m} / \mathrm{s}$ ends at the axial distance of about $35 \mathrm{~mm}$ in the low Mach number model. 
Constrained by the non-slip flow condition and the cooling effect on the anode, the results for the temperature and velocity obtained with both approaches are quite similar in the vicinity of the nozzle wall.

The current density of the order of $10^{8} \mathrm{~A} / \mathrm{m}^{2}$ is obtained in the vicinity of the cathode tip by both models (Fig. 10) in accordance with the distribution of the current density along the cathode (Fig. 7) set as a boundary condition for the MHD model. The contours of equal current density are only slightly more extended toward the outlet in the low Mach number model. The arc attachment at the nozzle wall is similar to a maximum current density of about $4 \times 10^{6}$ $\mathrm{A} / \mathrm{m}^{2}$ obtained in both models. The contours of the electric potential (Fig. 11) in both models look like similar up to $\mathrm{z} \sim 32 \mathrm{~mm}$ that in turn indicates close values of the gradients, i.e., similar values of the electric field. The gradient of the electric potential is slightly lower toward the outlet in the low Mach number model.

Figure 12 shows the predicted velocity (a), the speed of sound (b), and the Mach number (c) along the torch axis for both models. The results in Fig. 12 show less deviations of the velocity and Mach number from the two models in the upstream region but a larger discrepancy in the speed of sound. In the downstream region, the predicted values of the speed of sound are very close in both models, but the velocity and Mach number from the high Mach number model are well above those predicted by the low Mach number model. We notice that the Mach number exceeds

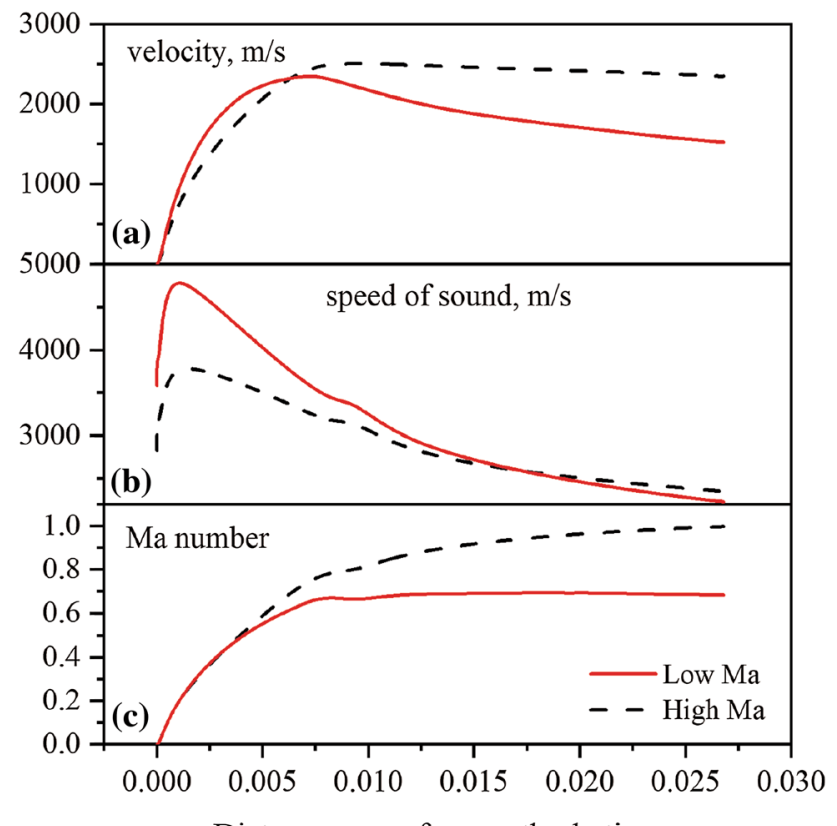

Distance away from cathode tip, $\mathrm{m}$

Fig. 12 Axial distribution of (a) velocity, (b) speed of sound, (c) Ma number from different models (the working conditions are the same as in Fig. 8) the limit of 0.3 , up to which the low Mach number approach is considered as justified.

The results in Fig. 12 indicate that the discrepancy may originate from the values of the pressure and density, by which the speed of sound is expressed: $a=(\gamma \times p / \rho)^{0.5}$, where $\gamma$ is the ratio of specific heats, $p$ is the absolute pressure, and $\rho$ is the mass density. Figure 13 shows the plasma density and the calculated gauge pressure (the pressure in excess of the atmospheric pressure).

For the sake of completeness of the analysis, the axial distribution of the temperature is further shown in Fig. 14. We notice that in the low Mach number model the mass density is taken as a temperature-dependent interpolation function, while in the high Mach number model the density is obtained from the ideal gas law $\left(\rho=M_{n} p / R T\right)$. It exceeds that in the low Mach number model for axial distances from the cathode tip of about $7 \mathrm{~mm}$ but becomes lower toward the outlet. This corresponds to the higher temperature predicted by the high Mach number for axial distances from the cathode tip beyond $10 \mathrm{~mm}$. A larger discrepancy between the predictions of both models is obtained in the gauge pressure, which is the main reason for the discrepancy in the values of the speed of sound in Fig. 12(b). The velocity is determined from the momentum equation (see Eq 2) with the pressure gradient on the righthand side. The results in Fig. 13 show for distances beyond approximately $8 \mathrm{~mm}$ almost no pressure gradient in the high Mach number case, while the pressure gradient is larger in the low Mach number case. This in turn leads to a very weak decrease in the velocity in the high Mach number case and a well-pronounced decrease in the low Mach number case. Despite the differences in the axial distributions of the velocity, pressure, and density reported above, the axial distributions of the temperature and in particular those of the magnitude of current density (Fig. 14), the electric field (Fig. 15a), and potential

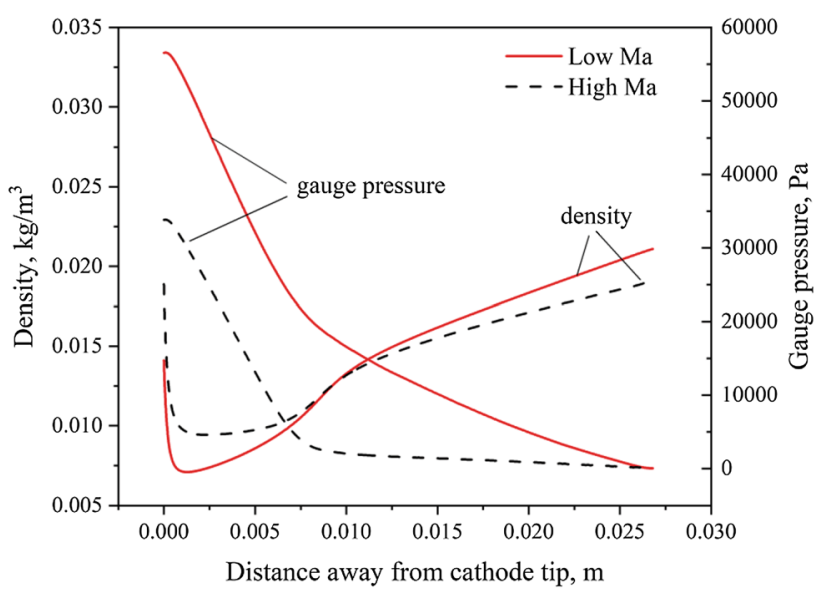

Fig. 13 Axial distribution of density and gauge pressure from different models (the working conditions are the same as in Fig. 8) 
(Fig. 15b) obtained by both models are quite similar. Small differences appear close to the cathode tip. This means that the electromagnetic part is slightly influenced by the different approaches applied for the solution of the fluid part of the physical problem close to the cathode tip. Here, the course of the electric potential and the electric field for the low Mach number model and the high Mach number model split from each other. The resolved image of the axial distribution of the electric potential (Fig. 15b) shows values at the cathode tip of $-25.5 \mathrm{~V}$ and $-26 \mathrm{~V}$ from the high and the low Mach number, respectively. This results in a difference of $0.5 \mathrm{~V}$ (only $2 \%$ ) in the voltage drop over the plasma bulk.

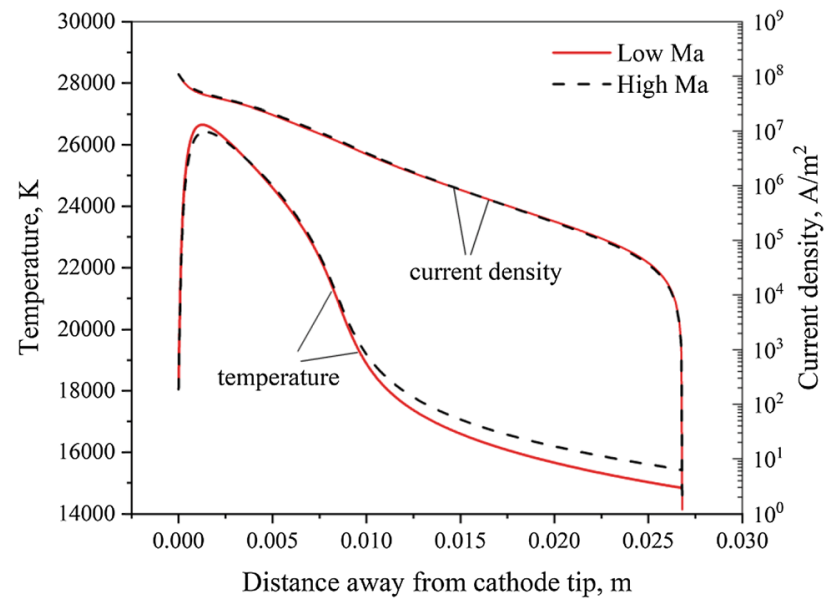

Fig. 14 Axial distribution of temperature and current density from different models (the working conditions are the same as in Fig. 8)
The self-consistent coupling of the LTE arc plasma to the cathode and its boundary layer in the present work is of significant importance for the predictive capability of the model of the plasma spray torch. The models' predictions of the arc voltage for various electric currents and gas flow rates are compared with experimental findings in Fig. 16. Given a voltage drop in the cathode boundary layer of roughly $8 \mathrm{~V}$, the predicted voltage would be far below the measured values if the contribution of the boundary layer has not been taken into account. That is why the approach combining the LTE plasma with the cathode and its boundary layer can be considered as the state of the art in arc plasma modeling (Ref 53). For a flow rate of 40 NLPM and a current of $600 \mathrm{~A}$, the predictions of both models are very close to each other as the predictions of the high Mach number model are closer to the experimental values. The predicted arc voltage by the high Mach number model remains closer to the experiment for a current of $600 \mathrm{~A}$ with the increase in the gas flow rate up to 80 NLPM. However, for a current of $800 \mathrm{~A}$ and flow rates of 40 and 60 NLPM, the arc voltage from the low Mach number model is a bit closer to the measured values. For a flow rate of 80 NLPM and an arc current of $800 \mathrm{~A}$, the predicted arc voltage by the high Mach number model is closer to the experiment. As it can be expected, the results from both models progressively differ from each other with the increase in the arc current and the gas flow rate, since these are conditions leading to higher Mach numbers.

Further data for comparison are presented in Table 2. The electric power is computed as the product of the electric current $(I)$ and discharge voltage $U_{d}$, i.e., $P_{d}=U_{d} \mathrm{I}$. The thermal efficiency from the experiment is obtained as
Fig. 15 Axial distribution of electric potential and electric field from different models (the working conditions are the same as in Fig. 8)

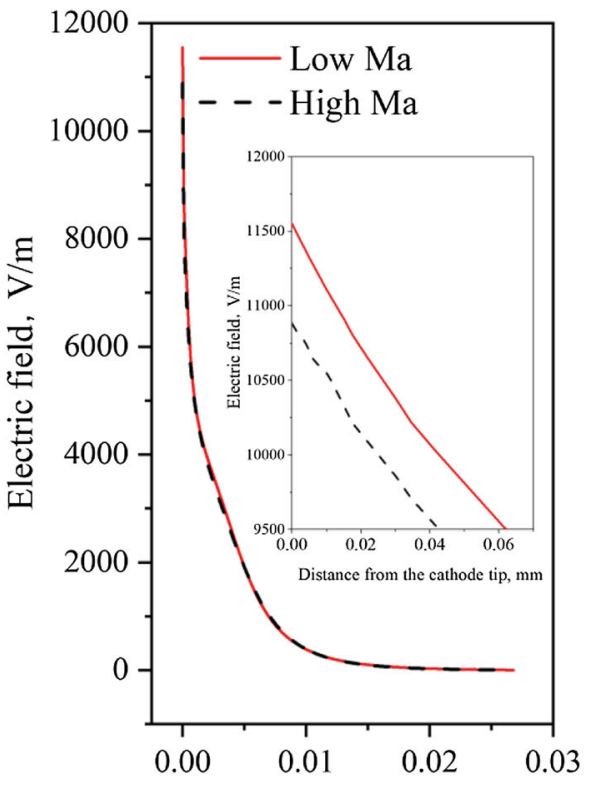

(a) Distance from the cathode tip, $m$

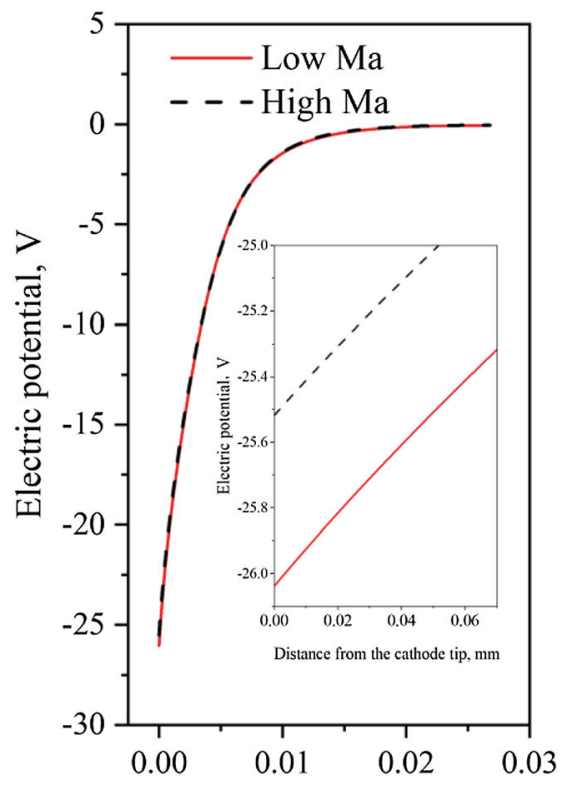

(b) Distance from the cathode tip, $m$ 
$\eta=\frac{P_{d}-Q}{P_{d}} \times 100 \%$ where $\mathrm{Q}$ denotes the power lost for cooling the electrodes. Its value is evaluated from measurements of the temperature of the cooling water. The predicted thermal efficiency is computed by the expression $\eta=\frac{\int_{s} \rho \cdot h \cdot u_{z} d s}{P_{d}} \times 100 \%$ where $h$ denotes the enthalpy, $u_{\mathrm{z}}$ is the axial velocity, and the integration is performed over the area $S$ of the outlet. The good agreement of the mean measured and the predicted voltage from both models results in a good agreement of the corresponding power values. The predicted thermal efficiency by the high Mach number model agrees well with the experimental one. The experimental and predicted values are between about $50 \%$ and $60 \%$ and are typical for operating conditions under consideration for conventional plasma spray torches (Ref 25). The low Mach number model predicts a thermal efficiency in agreement with the experiment for a current of $600 \mathrm{~A}$ and a flow rate of 40 NLPM. At higher flow rates, however, the low Mach number model underestimates the

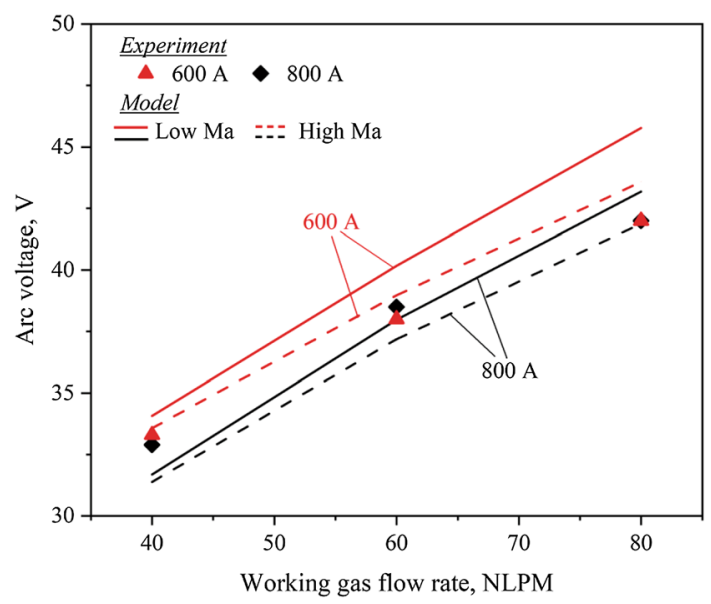

Fig. 16 Arc voltage values obtained in experiments (symbols) and modeling (lines). Triangles and diamonds correspond to an electric current of, respectively, $600 \mathrm{~A}$ and $800 \mathrm{~A}$. Solid and dash lines represent the results of the low and high Mach number models for current values of $600 \mathrm{~A}$ and $800 \mathrm{~A}$ thermal efficiency mainly due to the lower velocity predicted at the torch outlet (Fig. 12a).

Measurements inside the plasma spray torch considered in this work are not available at the current stage. Therefore, modeling predictions achievable in short time and over a broad range of operating conditions are advantageous for gaining an insight of the plasma parameters. The results of this study show that the high Mach number model is a promising candidate. Notice that the computational effort and robustness related to both models are quite similar on the computational platform COMSOL Multiphysics. This can be not the case on other computational platforms so that low Mach number models can be preferred to general compressible flow solvers.

\section{Conclusions}

In DC plasma spray torches operated at current values of several hundred Amperes, the velocity of the generated plasma jet can approach the speed of sound, i.e., Mach numbers close to one can be reached. Under such conditions, the description of the fluid flow can affect the models' predictions. In this work, a two-dimensional and stationary model of an LTE plasma has been coupled in a self-consistent way to the cathode and its boundary layer. The model is limited to the steady operating mode of the spray plasma torch. Both the low and high Mach number approaches for the description of a laminar and compressible flow have been implemented in the magnetohydrodynamic model of the plasma spray torch. The analysis of the results can be summarized as follows.

In general, the predicted pressure, plasma temperature, velocity, and electric potential differ to some extent.

- The maximum temperature value reached at a distance of about $2 \mathrm{~mm}$ from the cathode tip in the high Mach number model is slightly lower than that from the low Mach number model. Toward the outlet (distances from
Table 2 Experimental and predicted power $(\mathrm{Pd})$ and thermal efficiency $(\eta)$ for various operating conditions

\begin{tabular}{|c|c|c|c|c|c|c|c|}
\hline \multirow{2}{*}{$\begin{array}{c}\phi[\mathrm{NLPM}] \\
\mathrm{I}[\mathrm{A}]\end{array}$} & \multicolumn{2}{|l|}{40} & \multicolumn{2}{|c|}{60} & \multicolumn{2}{|c|}{80} & \multirow[t]{2}{*}{ Remark } \\
\hline & $P_{\mathrm{d}}[\mathrm{kW}]$ & $\eta[\%]$ & $P_{\mathrm{d}}[\mathrm{kW}]$ & $\eta[\%]$ & $P_{\mathrm{d}}[\mathrm{kW}]$ & $\eta[\%]$ & \\
\hline \multirow[t]{3}{*}{600} & $19.20 \pm 0.12$ & 49.5 & $23.0 \pm 0.2$ & 60.3 & $25.0 \pm 0.6$ & 60.4 & Experiment \\
\hline & 20.40 & 48.6 & 24.10 & 47.4 & 27.5 & 43.4 & Low Ma \\
\hline & 20.10 & 56.9 & 23.40 & 64.98 & 26.1 & 63.7 & High Ma \\
\hline \multirow[t]{3}{*}{800} & $26.0 \pm 0.3$ & 53.8 & $30.0 \pm 0.5$ & 57.6 & $33.0 \pm 0.9$ & 61.2 & Experiment \\
\hline & 25.3 & 46.3 & 30.4 & 44.9 & 34.5 & 40.9 & Low Ma \\
\hline & 25.1 & 53.6 & 29.7 & 60.6 & 33.5 & 61.0 & High Ma \\
\hline
\end{tabular}

Notations: $-\phi-$ flow rate, I-electric current. 
the cathode tip larger than $10 \mathrm{~mm}$ ), the high Mach number model predicts higher temperatures, but the difference is still below $4 \%$.

- The findings from the two approaches deviate stronger in the spatial velocity profiles.

Here, the high Mach number model predicts an axial profile that is by far more elongated than that from the low Mach number model.

- The larger discrepancy between the predictions of both models obtained in the gauge pressure results in different values of the speed of sound and hence in the predicted velocity.

- The predicted voltage drop over the arc column is only a bit lower in the high Mach number model. The difference in the models' predictions increases with the increase in the flow rate, but it does not exceed 5\%. The arc voltage obtained as the total of the voltage drop over the arc column and the voltage drop in the cathode boundary layer is in good agreement with experimental findings. The agreement is better with the voltage over the arc column obtained by the high Mach number model for higher flow rates and arc currents.

- The thermal efficiency computed by the high Mach number model agrees very well with the experimental one. The low Mach number model predicts a thermal efficiency in agreement with the experiment for a current of $600 \mathrm{~A}$ and a flow rate of 40 NLPM. At higher flow rates, however, the low Mach number model tends to underestimate the thermal efficiency.

- The results of both models show that the voltage drop in the cathode boundary layer is a substantial part of the arc voltage and that the self-consistent coupling of the cathode and LTE plasma submodels is advantageous in the modeling of plasma spray torches.

Acknowledgments This work was funded by the European Union and the Federal State of Germany Mecklenburg-Western Pomerania (Project number TBI-V-1-321-VBW-112).

Funding Open Access funding enabled and organized by Projekt DEAL.

Open Access This article is licensed under a Creative Commons Attribution 4.0 International License, which permits use, sharing, adaptation, distribution and reproduction in any medium or format, as long as you give appropriate credit to the original author(s) and the source, provide a link to the Creative Commons licence, and indicate if changes were made. The images or other third party material in this article are included in the article's Creative Commons licence, unless indicated otherwise in a credit line to the material. If material is not included in the article's Creative Commons licence and your intended use is not permitted by statutory regulation or exceeds the permitted use, you will need to obtain permission directly from the copyright holder. To view a copy of this licence, visit http://creativecommons. org/licenses/by/4.0/.

\section{References}

1. A. Vardelle, C. Moreau, N.J. Themelis and C. Chazelas, A Perspective on Plasma Spray Technology, Plasma Chem. Plasma Process., 2015, 35(3), p 491-509.

2. J.P. Trelles, C. Chazelas, A. Vardelle and J.V.R. Heberlein, Arc Plasma Torch Modeling, J. Therm. Spray Technol., 2009, 18(5), p 728-752.

3. C. Chazelas, J.P. Trelles and A. Vardelle, The Main Issues to Address in Modeling Plasma Spray Torch Operation, J. Therm. Spray Technol., 2017, 26(1-2), p 3-11.

4. C. Chazelas, J.P. Trelles, I. Choquet and A. Vardelle, Main Issues for a Fully Predictive Plasma Spray Torch Model and Numerical Considerations, Plasma Chem. Plasma Process., 2017, 37(3), p 627-651.

5. J.P. Trelles, E. Pfender and J.V.R. Heberlein, Non-Equilibrium Modeling of Arc Plasma Torches, J. Phys. D Appl. Phys., 2007, 40(19), p 5937-5952.

6. P. Liang and R. Groll, Numerical Study of Plasma-Electrode Interaction during Arc Discharge in a DC Plasma Torch, IEEE Trans. Plasma Sci., 2018, 46(2), p 363-372.

7. M. Tanaka, H. Terasaki, M. Ushio and J. Lowke, A Unified Numerical Modeling of Stationary Tungsten-Inert-Gas Welding Process, Metall. Mater. Trans. A., 2002, 33(7), p 2002-2043.

8. M. Alaya, C. Chanzelas, G. Mariaux and A. Vardelle, ArcCathode Coupling in the Modelling of a Conventional DC Plasma Torch, J. Therm. Spray Technol., 2015, 24(1-2), p 3-10.

9. M. Alaya, C. Chanzelas and A. Vardelle, Parametric Study of Plasma Torch Operation Using a MHD Model Coupling the Arc and Electrodes, J. Therm. Spray Technol., 2016, 25(1-2), p 36-43.

10. J. Xiang, K. Tanaka, F. Chen, M. Shigeta, M. Tanaka and A.B. Murphy, Modelling and Measurements of Gas Tungsten Arc Welding in Argon-Helium Mixtures with Metal Vapour, Welding in the World, 2021, 65, p 767-783.

11. J. Haidar, Non-equilibrium Modelling of Transferred Arcs, $J$. Phys. D: Appl. Phys., 1999, 32(3), p 263-272.

12. M. Baeva and D. Uhrlandt, Plasma Chemistry in the FreeBurning Ar Arc, J. Phys. D: Appl. Phys., 2013, 46(32), p 325202.

13. M.S. Benilov, Understanding and Modelling Plasma-Electrode Interaction in High- Pressure Arc Discharges: A Review, J. Phys. D Appl. Phys., 2008, 41(14), p 144001.

14. J.J. Gonzalez, F. Cayla, P. Freton and P. Teulet, Two-Dimensional Self-Consistent Modelling of the Arc/Cathode Interaction, J. Phys. D Appl. Phys., 2009, 42(14), p 145204.

15. M. Lisnyak, M.D. Cuhna, J.-M. Bauchire and M.S. Benoliv, Numerical Modelling of High-Pressure Arc Discharge: Matching the LTE Arc Core with the Electrodes, J. Phys. D Appl. Phys., 2017, 50(31), p 315203.

16. A.J. Shirvan, I. Choquet, H. Nilsson and H. Jasak, Coupling Boundary Condition for High- Intensity Electric Arc Attached on a Non-Homogeneous Refractory Cathode, Comput. Phys. Commun., 2018, 222, p 31-45.

17. M. Baeva, M.S. Benilov, N.A. Almeida and D. Uhrlandt, Novel Non-Equilibrium Modelling of a DC Electric Arc in Argon, $J$. Phys. D Appl. Phys., 2016, 49(24), p 245205.

18. C. Mohsni, M. Baeva, St. Franke, S. Gortschakow, Z. Araoud and K. Charrada, Effect of a Bidirectional Coupling of a LTE Arc Column to a Refractory Cathode in Atmospheric Pressure Argon, Phys. Plasmas, 2020, 27(7), p 073514.

19. ANSYS Fluent. Fluent 6.3 Documentation. Fluent Inc., Lebanon, NH, 2006.

20. P. Freton, J.J. Gonzalez and A. Gleizes, Comparison Between a Two- and a Three- Dimensional Arc Plasma Configuration, $J$. Phys. D Appl. Phys., 2000, 33(19), p 2442-2452. 
21. R. Zhukovskii, C. Chazelas, A. Vardelle, V. Rat and B. Distler, Effect of Electromagnetic Boundary Conditions on Reliability of Plasma Torch Models, J. Therm. Spray Technol., 2020, 29, p 894-907.

22. COMSOL Multiphysics ${ }^{\circledR}$ v. 5.6. www.comsol.com (Stockholm: COMSOL)

23. F4MB-XL BRO-0006.6 Atmospheric Plasma Spray Solutions, https://www.oerlikon.com/metco/de/produkte-services/beschich tungssysteme/thermisches-spritzen/brenner-und-pistolen/plasma/ f4mb-xl-plasmaspritzbrenner/

24. Tungsten-Copper Plasma Spray Electrodes and Nozzles, https:// www.plansee.com/de/produkte/komponenten/bauteile-fuerbeschichtungsanlagen/plasmaspritzelektroden.html

25. P. Fauchais, J.V.R. Heberlein and M. Boulos, Thermal Spray Fundamentals: From Powder to Part, Springer, New York, 2014.

26. Z. Duan and J. Heberlein, Arc Instabilities in a Plasma Spray Torch, J. Therm. Spray Technol., 2002, 11(1), p 44-51.

27. K. Bobzin, M. Öte, M.A. Knoch, I. Alkhasli and H. Heinemann, High-Speed Video Analysis of the Process Stability in Plasma Spraying, J. Therm. Spray Technol., 2021, 30(1), p 987-1000.

28. A.B. Murphy and C.J. Arundel, Transport Coefficients of Argon, Nitrogen, Oxygen, Argon-Nitrogen, and Argon-Oxygen Plasmas, Plasma Chem. Plasma Process., 1994, 14(4), p 451-490.

29. A.B. Murphy, Transport Coefficients of Air, Argon-Air, Nitrogen-Air, and Oxygen-Air Plasmas, Plasma Chem. Plasma Process., 1995, 15(2), p 279-307.

30. B. Pateyron, G. Delluc, and N. Calve, T\&T Winner-Software for Thermo-Chemistry, Univ. Limoges, 2015, 87051 Limoges Cedes, France

31. J. Menart and S. Malik, Net Emission Coefficients for Argon-Iron Thermal Plasmas, J. Phys. D Appl. Phys., 2002, 35(9), p 867-874.

32. E. Lassner and W.D. Schubert, Tungsten: Properties, Chemistry, Technology of the Element. Alloys, and Chemical Compounds (Kluwer Academic/Plenum Publishers, 1999).

33. D. Smith, I.V. Altovsky, V.R. Barabash, and J. Beeston, ITER Blanker, Shield and Material Database, ITER Documentation Series (IAEA, Vienna, 1991), Vol. 29.

34. Y. S. Touloukian, Thermal Conductivity: Metallic Elements and Alloys (IFI/Plenum, 1970).

35. C. Cagran, Thermal Conductivity and Thermal Diffusivity of Liquid Copper, Dipl. Thesis,Techn. Univ. Graz, 2000

36. T.L. Bergman, A.S. Lavine, F.P. Incropera and D.P. Dewitt, Fundamentals of Heat and Mass Transfer, Wiley, NY, 2011.

37. M.S. Benilov and A. Marotta, A Model of the Cathode Region of Atmospheric Pressure Arcs, J. Phys. D: Appl. Phys., 1995, 28(9), p 1869-1882.
38. S. Fomenko, Electron Emission Properties of Materials, Naukova Dumka, Kiev, 1981.

39. M. Baeva, T. Zhu, T. Kewitz, H. Testrich, and R. Foest, SelfConsistent Cathode-Plasma Coupling and Role of the Fluid Flow Approach in Torch Modelling-Dataset (https://doi.org/10. 34711/INPTDAT.384)

40. M.S. Benilov and M.D. Cuhna, Heating of Refractory Cathodes by High-Pressure Arc Plasmas I, J. Phys. D Appl. Phys., 2002, 35(14), p 1736-1750.

41. M.S. Benilov, Theory and Modelling of Arc Cathodes, Plasma Sources Sci. Technol., 2002, 3A, p A49-A54.

42. N.A. Almeida, M.D. Cuhna and M.S. Benilov, Computing Anode Heating Voltage in High-Pressure Arc Discharges and Modelling Rod Electrodes in DC and AC Regimes, J. Phys. D Appl. Phys., 2017, 50(38), p 385203.

43. J.J. Lowke, R. Morrow and J. Haidar, A Simplified Unified Theory of Free Arcs and Their Electrodes, J. Phys. D Appl. Phys., 1997, 30(14), p 2033-2042.

44. J. Heberlein, J. Mentel and E. Pfender, The Anode Region of Electric Arcs: A Survey, J. Phys. D Appl. Phys., 2010, 43(2), p 023001.

45. V.A. Nemchinsky, Arc Discharge Anode Reattachment: Simple Model, IEEE Trans. Plasma Sci., 2014, 42(12), p 4026-4030.

46. J.D. Anderson, Modern Compressible Flow, 3rd ed., McGrawHill, 2003.

47. T. Poinsot and D. Veynante, Theoretical and Numerical Combustion, 2nd ed., Edwards, 2005.

48. J.D. Tannehill, D.A. Anderson and R.H. Pletcher, Computational Fluid Mechanics and Heat Transfer, 2nd ed. Taylor \& Francis, Routledge, 1997.

49. F.M. White, Viscous Fluid Flow, 3rd ed. McGraw-Hill, NY, 2006.

50. Engineering ToolBox, (2004). STP - Standard Temperature and Pressure \& NTP - Normal Temperature and Pressure.

51. B. Chiné, A 2D Model of a DC Plasma Torch. In: Comsol Conference 2016. pp. 12-14.

52. M. Baeva, Non-Equilibrium Modeling of Tungsten-Inert Gas Arcs, Plasma Chem. Plasma Process., 2017, 37(2), p 341-370.

53. M.S. Benilov, Modeling the Physics of Interaction of HighPressure Arcs with Their Electrodes: Advances and Challenges, J. Phys. D: Appl. Phys., 2020, 53(1), p 013002.

Publisher's Note Springer Nature remains neutral with regard to jurisdictional claims in published maps and institutional affiliations. 